\title{
SURFACE ROUGHNESS OF MONOLITHIC ZIRCONIA AND GOLD ALLOY AFTER WEAR SIMULATION AGAINST HUMAN ENAMEL
}

\author{
Khaled Haggag *, Muhammad Abbas ** and Zainab El Sharkawy ${ }^{* * *}$
}

\begin{abstract}
Purpose: To evaluate the effect of simulated wear against human enamel on the surface roughness of monolithic zirconia and gold alloy under different occlusal loads.

Materials and Methods: Forty rectangular plate specimens $(6 \times 6 \times 2) \mathrm{mm}$, were prepared from monolithic zirconia (Bruxzir, $n=20$ ) and type IV gold (Begostar, $n=20$ ) forming two experimental groups. Forty premolar teeth freshly extracted for orthodontic purpose were sectioned mesio-distally and only the cusp tips of the buccal halves were used as antagonists in the wear simulation testing procedure. All of the specimens were mounted to chewing simulator with the cusp antagonists, half of them were subjected to (50000 chewing cycles under $50 \mathrm{~N}$ load), the other half subjected to ( 50000 chewing cycles under $150 \mathrm{~N}$ load) cyclic loading. Data were submitted to two-way ANOVA, and statistical significance was set at $\mathrm{p}<0.05$.
\end{abstract}

Results: With low load $(50 \mathrm{~N})$, it was found that gold alloy group recorded statistically significant higher roughness change mean value $(0.00085 \pm 0.001 \mathrm{Ra})$ than Bruxzir group mean value $(-0.00079 \pm 0.0023 \mathrm{Ra})$. The difference between groups was statistically significant as indicated by student $\mathrm{t}$-test $(\mathrm{t}=2.08, \mathrm{p}=0.0492<0.05)$. While, enamel cusp antagonist of gold alloy group recorded non-statistically significant higher roughness change mean value $(0.01867 \pm 0.024 \mathrm{Ra})$ than enamel cusp antagonist of Bruxzir group mean value $(0.016567 \pm 0.0013 \mathrm{Ra})$. The difference between groups was statistically non-significant as indicated by student $t$-test $(t=1.7, p=0.1043>$ $0.05)$. With high load $(150 \mathrm{~N})$, it was found that gold alloy group recorded statistically non-significant higher roughness change mean value $(0.00135 \pm 0.0017 \mathrm{Ra})$ than Bruxzir group mean value $(-0.00052 \pm 0.003 \mathrm{Ra})$. The difference between groups was statistically non-significant as indicated by student $\mathrm{t}$-test $(\mathrm{t}=1.648, \mathrm{p}=0.1135>0.05)$. While, enamel cusp antagonist of gold alloy group recorded statistically non-significant higher roughness loss mean value $(0.00219 \pm 0.005 \mathrm{Ra})$ than enamel cusp antagonist of Bruxzir group mean value $(-0.00021 \pm 0.005 \mathrm{Ra})$. The difference between groups was statistically non-significant as indicated by student $\mathrm{t}$-test $(\mathrm{t}=1.15, \mathrm{p}=0.2615>0.05)$.

Conclusions: 1. Monolithic zirconia do not become as rough as type IV gold when subjected to simulated mastication cycles at low $(50 \mathrm{~N})$ load, although they were not significantly different from each other at high $(150 \mathrm{~N})$ load. 2. Although being non-significant, there was a correlation between roughness change of both monolithic zirconia and gold substrates, and that of their enamel antagonists.

\footnotetext{
* Assistant Professor, Crowns and Bridges Department, Faculty of Dental Medicine, Al Azhar University, Egypt. ** Assistant Professor, Dental Biomaterials Department, Faculty of Dental medicine, Al-Azhar University, Egypt, *** Lecturer, Crowns and Bridges Department, Faculty of Dental Medicine for Girls, Al Azhar University, Egypt
} 


\section{INTRODUCTION}

Gold had been widely employed for many decades as the restorative material of choice due to its biocompatibility, low abrasiveness of opposing natural teeth, and durability. ${ }^{1,2}$ However their esthetic limitations led to the advent of porcelain. The inferior tensile strength, hardness, brittleness, and resistance to fracture of conventional feldspathic ${ }^{3}$ were overcome by introduction of newer metal free ceramics.

Zirconia, one of the more recently introduced ceramics in prosthetic dentistry with outstanding mechanical properties and acceptable clinical performance even as long-span and cantilever fixed dental prostheses in stress-bearing regions. ${ }^{4,5}$ It was first introduced as core material layered with veneering porcelain, however, chipping has been reported to be a major complication. ${ }^{4,6,7,8}$ therefore, monolithic or full-contour zirconia are enjoying growing popularity in dental applications., ${ }^{910}$

The surface roughness of restorative materials not only has been regarded as the result of restoration wear, it is also considered as the cause of wear of antagonistic teeth and restorations. This was also confirmed by Elmaria et al ${ }^{11}$ who evaluated enamel wear caused by 3 ceramic substrates in the glazed and polished conditions, there was a significant correlation between Ra of the substrate and enamel wear. Wear takes place when 2 materials slide against each other. It can be attributed to adhesion, abrasion, corrosion, and surface fatigue. ${ }^{12}$ Ideally, wear resistance of the restorative material and enamel should be similar, ${ }^{13}$ however many restorative dental materials can change the wear rate of antagonistic natural teeth due to mismatched wear properties. ${ }^{12,14,15}$ Extreme, long term abrasiveness may result in loss of vertical dimension, poor esthetics, and increased tooth sensitivity. ${ }^{16-18}$ It can also negatively affect the esthetic and functional outcome of occlusal rehabilitations..$^{14,19-22}$

The aim of this in vitro study was to evaluate the surface roughness of monolithic zirconia compared with type IV gold, subjected to 50,000 mastication simulation cycles versus human enamel cusps. The null hypothesis tested was that the wear depth and surface roughness would not affected by type of material, the load related to simulated mastication, and that for each material, no difference would be found in enamel surface roughness compared with baseline.

\section{MATERIALS AND METHODS}

A total of forty $1^{\text {st }}$ premolars were selected for this study. The selection criteria were based on teeth condition. All teeth were examined under $4 x$ magnification loops (HEINE Optotechnik GmbH \& Co.KG) for any cracks, caries or old restorations. All defected teeth were excluded. The teeth were then splitted mesio-distally to use only the buccal half that was mounted to Jakub's chuck (of the chewing simulator) leaving only the buccal cusp exposed for testing procedure. All teeth were stored in distilled water at the room temperature until the tests were being carried out.

A total of 40 square-shaped $(6 \times 6 \times 2 \mathrm{~mm})$ samples were prepared from monolithic zirconia (Bruxzir, $\mathrm{n}=20$ ) and type IV gold (Begostar, $\mathrm{n}=20$ ).

Preparation of gold specimens: (Wax pattern construction)

Square plate samples $(6 \times 6 \times 2 \mathrm{~mm})$ was prepared from CAD/Ivory disc (ONDENT TIBBI MALZ, Turkey) by using an electrical high-precision saw (Isomet 4000, micro saw, Buehler Ltd, USA) under water cooling system with two anticorrosive agents, rotating at a speed $2500 \mathrm{rpm}$ and feeding rate $5 \mathrm{~mm} /$ $\mathrm{min}$. The diamond disc used is of $0.3 \mathrm{~mm}$ thickness. The plates were then assembled with modeling wax to form a single wax pattern that was ready for burnout and casting. The gold specimens were then constructed using the traditional lost wax technique: Spruing, investing using phosphate bonded investment (Bellavest, BEGO, PARASKOP, Germany), wax elimination in the burnout furnace, 
graphite crucible was used for melting of gold, casting was then accomplished in the casting machine Furnax compact high-frequency induction casting machine (BEGO. PARASKOP, Germany), divesting. The casting was then sectioned using cutting disc (Frank Dental GmbH, Germany) to separate the gold plates from each other. Finishing and polishing procedure was accomplished using Gold Polishing Classic Plastic Kit (Shofu Dental Corp. California, USA). which used for finishing and super-polishing of cast gold and precious alloys: (Brown disc used for pre-polishing, Green disc used for polishing. Super green disc used for super-polishing).

\section{Preparation of the zirconia specimens}

Square plate samples $(7.5 \times 7.5 \times 2.5) \mathrm{mm}$ were prepared from Pre-sintered Bruxzir zirconia milling blanks by using an electrical high-precision saw (Isomet 4000, micro saw, Buehler Ltd, USA) under water cooling system with two anticorrosive agents, rotating at a speed $2500 \mathrm{rpm}$ and feeding rate $5 \mathrm{~mm} / \mathrm{min}$. The diamond disc used is of $0.3 \mathrm{~mm}$ thickness. The specimens were cut oversized by approximately $25 \%$ to compensate for the shrinkage occurred during sintering to full density specified by the enlargement factor on the product label, to give plates of final dimensions $6 \times 6 \times 2 \mathrm{~mm}$ approximately. The sintering process was proceeded in the Nabertherm High-temperature bottom loading furnace LHT 02/17 LB speed with rapid cooling function (Nabertherm $\mathrm{GmbH}$, Germany) by using the preset program of Bruxzir as recommended by manufacturer. The finishing and polishing procedure was done according to manufacturer instructions using DIASYNT Zirconia finishing and polishing kit (EVE Ernst Vetter GmbH, Germany).

\section{Wear simulation}

The two-body wear testing was performed using a programmable logic-controlled equipment (Four stations multimodal ROBOTA chewing simulator $\{$ Figure,1\}) Integrated with thermo-cyclic protocol operated on servo-motor (Model ACH-09075DC-T, AD-Tech Technology CO., LTD., Germany). The chewing simulator has four chambers simulating the vertical and horizontal movements simultaneously in the thermodynamic condition. Each of the chambers consists of an upper Jacob's chuck as tooth antagonist holder that can be tightened with a screw and a lower plastic sample holder specially designed with a square depression having the same dimensions of the specimen to be tested. The plastic holder is fixed in the lower chamber that contain distilled water to be used during testing procedures.

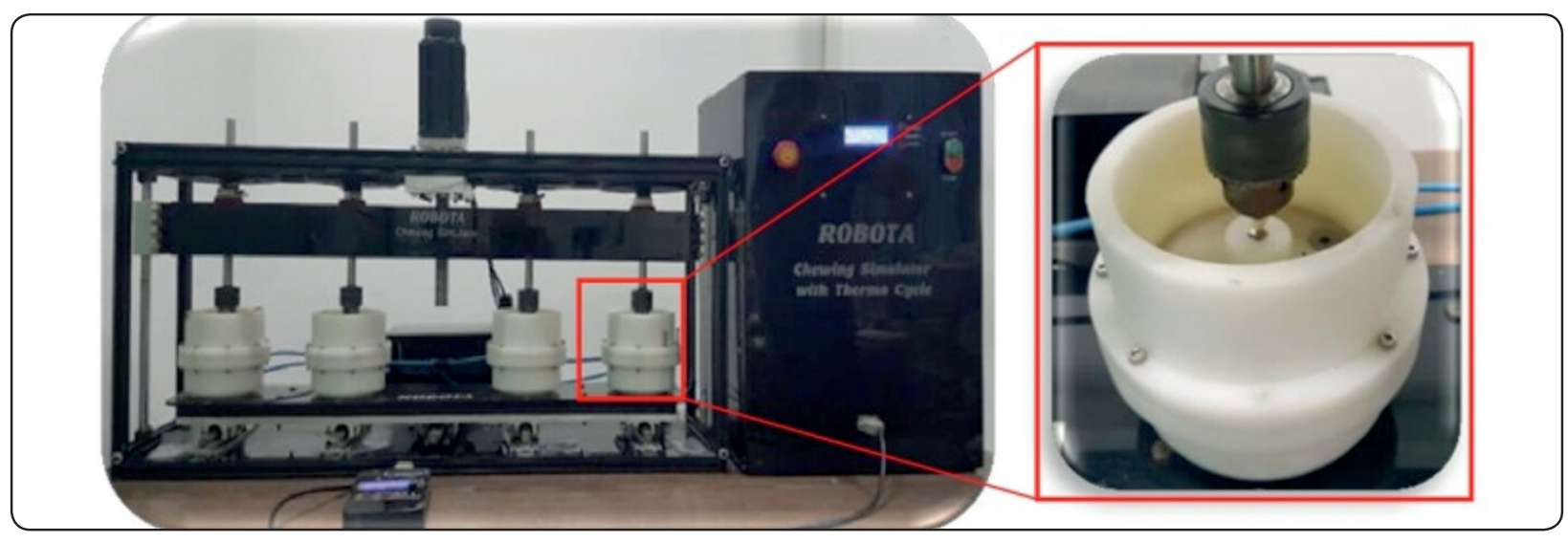

Fig. (1): Chewing simulator with tooth-material assembly in place 
Both groups samples (gold and bruxzir and their corresponding teeth specimens) were mounted and tested sequentially under the two sets of loads (Low/ high load) which were 50/150 $\mathbf{N}$ for a number of 50000 cycles under the wear testing parameters mentioned in (Table 1).

TABLE (1) Wear simulation testing parameters:

\begin{tabular}{|c|c|}
\hline Vertical movement & $1 \mathrm{~mm}$ \\
\hline Horizontal movement & $3 \mathrm{~mm}$ \\
\hline Rising speed & $60 \mathrm{~mm} / \mathrm{s}$ \\
\hline Descending speed & $40 \mathrm{~mm} / \mathrm{s}$ \\
\hline Forward speed & $60 \mathrm{~mm} / \mathrm{s}$ \\
\hline Backward speed & $40 \mathrm{~mm} / \mathrm{s}$ \\
\hline Cycle frequency & $1.6 \mathrm{~Hz}(96 \mathrm{cycle} / \mathrm{min})$ \\
\hline Time of 50000 cycles & $8.68 \mathrm{~h}$ \\
\hline Weight per specimen & $50 \mathrm{~N}$ and $150 \mathrm{~N}$ \\
\hline
\end{tabular}

\section{Roughness evaluation}

All teeth specimens and experimental materials samples (bruxzir and gold) were evaluated before and after wear simulation using USB digital surface profile gauge, cut-off $-0.25 \mathrm{~mm}$ (Elcometer 224/2, Elcometer Instruments, Great Britain) and data were recorded using computer software (Elcomaster 2,
Elcometer Instruments). The surface profile needle (radius of $2.5 \mu \mathrm{m}$ ) was positioned perpendicular over each test specimen performing five readings in different locations of the sample surface. After the five readings, the mean surface roughness values were obtained.

\section{Statistical analysis}

Data analysis was performed in several steps. Initially, descriptive statistics for each group results. Student t-test was performed between both materials and enamel cusp groups before and after wear simulation. Two-way analysis of variance (ANOVA) test of significance was done for comparing variables affecting mean values (experimental material groups and load). Statistical analysis was performed using Asistat 7.6 statistics software (Campina Grande, Paraiba state, Brazil) for Windows. $\mathrm{P}$ values $\leq 0.05$ are considered to be statistically significant in all tests.

\section{RESULTS}

The mean values and standard deviations (SD) for roughness measured by $(\mathrm{Ra}=\mu \mathrm{m})$ recorded on both materials and enamel cusp antagonist as function of load application before and after 50000 wear simulation cycles summarized in table (2) and graphically represented in figure (2).

TABLE (2) Roughness results (Mean values $\pm \mathrm{SD}$ ) for experimental groups and enamel cusp antagonist as function of load application before and after wear simulation

\begin{tabular}{|c|c|c|c|c|c|}
\hline \multirow{2}{*}{\multicolumn{2}{|c|}{ Variables }} & \multicolumn{2}{|c|}{ Samples } & \multicolumn{2}{|c|}{ Antagonist } \\
\hline & & Before & After & Before & After \\
\hline \multirow{2}{*}{$\begin{array}{c}\text { Low load } \\
\quad(50 \mathrm{~N})\end{array}$} & Bruxzir & $0.251367 \pm 0.001$ & $0.252158 \pm 0.002$ & $0.259383 \pm 0.003$ & $0.259467 \pm 0.0022$ \\
\hline & Gold alloy & $0.251392 \pm 0.0008$ & $0.250542 \pm 0.0012$ & $0.259383 \pm 0.0027$ & $0.240717 \pm 0.025$ \\
\hline \multirow{2}{*}{$\begin{array}{c}\text { High } \\
\text { load } \\
150(N)\end{array}$} & Bruxzir & $0.2520167 \pm 0.0022$ & $0.252533 \pm 0.002$ & $0.260133 \pm 0.0021$ & $0.260342 \pm 0.0028$ \\
\hline & Gold alloy & $0.25063 \pm 0.0006$ & $0.249283 \pm 0.0013$ & $0.258767 \pm 0.0017$ & $0.256575 \pm 0.0047$ \\
\hline
\end{tabular}




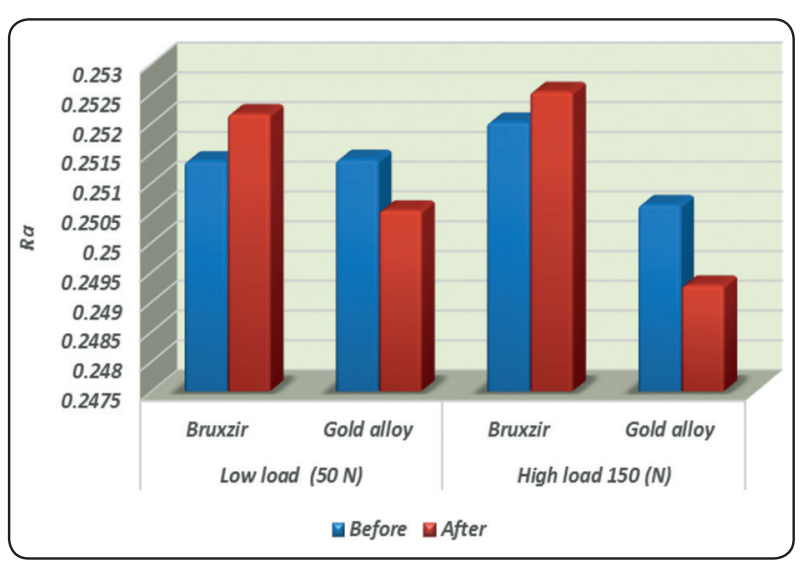

Fig. (2) Column chart showing roughness mean values for experimental groups as function of load application before and after wear simulation

\section{Under low load (50 N)}

\section{In experimental groups}

It was found that gold alloy group recorded statistically significant higher roughness change mean value $(0.00085 \pm 0.001 \mathrm{Ra})$ than Bruxzir group mean value $(-0.00079 \pm 0.0023 \mathrm{Ra})$. The difference between groups was statistically significant as indicated by student $\mathrm{t}$-test $(\mathrm{t}=2.08, \mathrm{p}=0.0492$ $<0.05)$.

\section{In enamel cusp antagonist groups}

It was found that enamel cusp antagonist of gold alloy group recorded non-statistically significant higher roughness change mean value

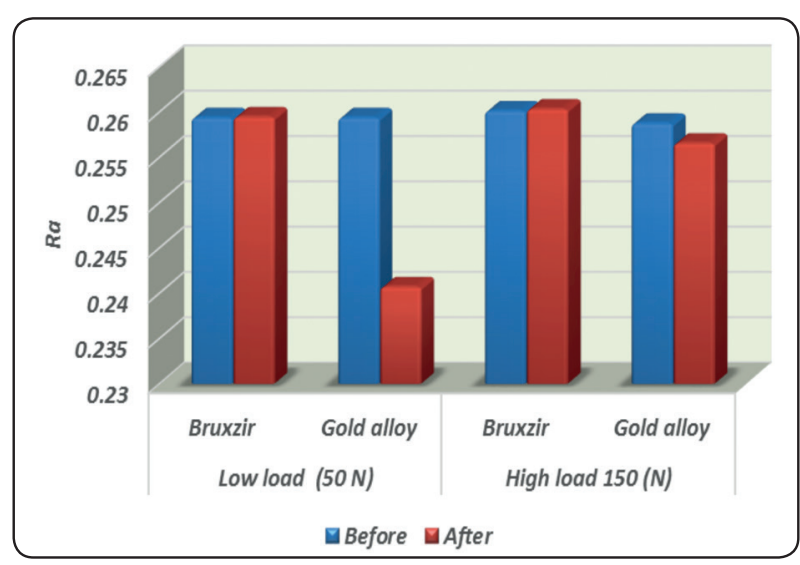

Fig. (3) Column chart showing roughness mean values for enamel cusp antagonist groups as function of load application before and after wear simulation

$(0.01867 \pm 0.024 \mathrm{Ra})$ than enamel cusp antagonist of Bruxzir group mean value $(0.016567 \pm 0.0013 \mathrm{Ra})$. The difference between groups was statistically non-significant as indicated by student $\mathrm{t}$-test $(\mathrm{t}=1.7$, $\mathrm{p}=0.1043>0.05)$.

\section{Under high load (150 N)}

\section{In experimental groups}

It was found that gold alloy group recorded statistically non-significant higher roughness change mean value $(0.00135 \pm 0.0017 \mathrm{Ra})$ than Bruxzir group mean value $(-0.00052 \pm 0.003 \mathrm{Ra})$. The difference between groups was statistically nonsignificant as indicated by student $\mathrm{t}$-test $(\mathrm{t}=1.648$, $\mathrm{p}=0.1135>0.05)$.

TABLE (3) Roughness change results (Mean values \pm SD) for experimental groups $s$ and enamel cusp antagonist after wear simulation under low load application $(50 \mathrm{~N})$

\begin{tabular}{|c|c|c|c|c|c|c|c|}
\hline \multirow{3}{*}{\multicolumn{2}{|c|}{ Variables }} & \multicolumn{3}{|c|}{ Samples } & \multicolumn{3}{|c|}{ Antagonist } \\
\hline & & \multirow{2}{*}{ Mean \pm SD } & \multicolumn{2}{|c|}{$95 \% \mathrm{CI}$} & \multirow{2}{*}{ Mean \pm SD } & \multicolumn{2}{|c|}{$95 \% \mathrm{CI}$} \\
\hline & & & Lower & Upper & & Lower & Upper \\
\hline \multirow{2}{*}{$\begin{array}{c}\text { Low load } \\
(50 \mathrm{~N})\end{array}$} & Bruxzir & $-0.0008 \pm 0.0023$ & -0.0022 & 0.0007 & $-0.000083 \pm 0.004$ & -0.0026 & 0.0025 \\
\hline & Gold alloy & $0.00085 \pm 0.001$ & -0.0001 & 0.0018 & $0.01867 \pm 0.024$ & -0.0056 & 0.0429 \\
\hline t-test & $P$ value & \multicolumn{3}{|c|}{$0.0492 *$} & \multicolumn{3}{|c|}{$0.1043 \mathrm{~ns}$} \\
\hline
\end{tabular}


TABLE (4) Roughness change results (Mean values \pm SD) for experimental groups and enamel cusp antagonist after wear simulation under high load application $(150 \mathrm{~N})$

\begin{tabular}{|c|c|c|c|c|c|c|c|}
\hline \multirow{3}{*}{\multicolumn{2}{|c|}{ Variables }} & \multicolumn{3}{|c|}{ Samples } & \multicolumn{3}{|c|}{ Antagonist } \\
\hline & & \multirow{2}{*}{ Mean $\pm \mathrm{SD}$} & \multicolumn{2}{|c|}{$95 \% C I$} & \multirow{2}{*}{ Mean $\pm \mathrm{SD}$} & \multicolumn{2}{|c|}{$95 \% C I$} \\
\hline & & & Lower & Upper & & Lower & Upper \\
\hline \multirow{2}{*}{$\begin{array}{c}\text { High load } \\
(150 \mathrm{~N})\end{array}$} & Bruxzir & $-0.00052 \pm 0.003$ & -0.00276 & 0.0017 & $-0.00021 \pm 0.005$ & -0.00033 & 0.0028 \\
\hline & Gold alloy & $0.00135 \pm 0.0017$ & 0.00027 & 0.0024 & $0.00219 \pm 0.005$ & -0.00122 & 0.0056 \\
\hline t-test & P value & \multicolumn{3}{|c|}{$0.1135 \mathrm{~ns}$} & \multicolumn{3}{|c|}{$0.2615 \mathrm{~ns}$} \\
\hline
\end{tabular}

CI; Confidence intervals

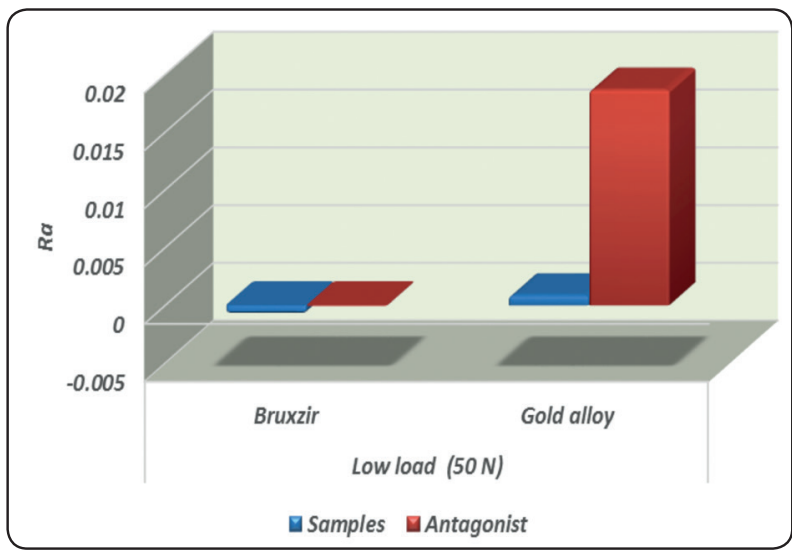

Fig. (4) Column chart showing roughness change mean values for experimental groups and enamel cusp antagonist after wear simulation under low load application $(50 \mathrm{~N})$

\section{In enamel cusp antagonist groups}

It was found that enamel cusp antagonist of gold alloy group recorded statistically non-significant higher roughness loss mean value $(0.00219 \pm 0.005$ $\mathrm{Ra}$ ) than enamel cusp antagonist of Bruxzir group mean value $(-0.00021 \pm 0.005 \mathrm{Ra})$. The difference between groups was statistically non-significant as indicated by student $\mathrm{t}$-test $(\mathrm{t}=1.15, \mathrm{p}=0.2615>0.05)$.

Regardless to load, totally it was found that gold alloy group recorded statistically non-significant higher roughness change mean value than Bruxzir group mean value as indicated by two-way ANOVA test $(p=0.8712>0.05)$

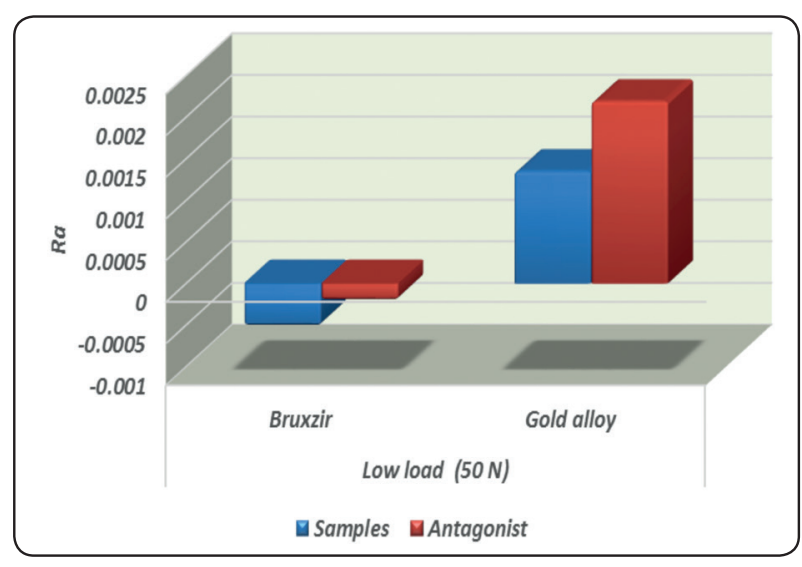

Fig. (5) Column chart showing roughness change mean values for experimental groups and enamel cusp antagonist after wear simulation under high load application $(150 \mathrm{~N})$

Irrespective of material, totally it was found that high load $150(\mathrm{~N})$ group recorded statistically nonsignificant higher roughness change mean value than low load $50(\mathrm{~N})$ group mean value as indicated by two-way ANOVA test $(\mathrm{p}=0.5772>0.05)$

\section{DISSCUSSION}

Gold alloy has long been believed as an ideal restorative material for fabricating dental crowns due to its mostly similar wear characteristics to those of human enamel. ${ }^{23}$ By increasing patient needs for more esthetic restorations that mimicked natural tooth color have led to the increased use of ceramic materials. ${ }^{24}$ 
Today many different all-ceramic systems known for their high biocompatibility, strength, and excellent esthetics, are available and can naturally imitate the natural human tooth characteristics..$^{25,26}$ The availability of computer-aided design and manufacture CAD/CAM has allowed well-fitted frameworks fabrication for fixed prosthesis from high-strength polycrystalline ceramics, like partially stabilized zirconia (PSZ). ${ }^{6,27,28}$

Zirconia is a polymorphic, multiphase material with suppression ability of crack progression through volume extension caused by the transformation toughening mechanism, ${ }^{29}$ leading to higher fracture strength, greater hardness and more wide clinical applications than other conventional porcelains..$^{29,30}$ Porcelain veneers of such opaque zirconia cores are generally prone to fracture because of weak interface, hence the advent of non-veneered, monolithic zirconia restorations with increased translucency was achieved by modifications of the fabrication process and the sintering procedures $^{31}$ Additionally, the use of these crowns provide the advantage of more conservative preparation plus eliminating the technique sensitivity of veneering procedures. $^{32}$

Unlike metals that exhibit some ductile behavior, many studies observed that ceramic materials wear mostly by abrasion and microfractures of the surface, ${ }^{33-36}$ so wear seems to be more correlated to surface roughness and fracture resistance than hardness values. ${ }^{37-39}$ Tooth wear is a complex process, both attrition of occlusal surfaces of teeth by direct contact, and abrasion in the presence of food particles could take place during mastication. Wear rate can be altered by the introduction of abraded restorative material. ${ }^{40}$ This occurs mainly in adhesive wear type, where loose fragments of one body adhere to the other body, leading to wear of substrate. ${ }^{41}$ Seghi et al ${ }^{33}$ stated that the wear rate of a restorative material should be equal to that of enamel. Moreover, the wear of enamel opposing enamel is $20-40 \mu \mathrm{m} /$ year as reported by Lambrechts et al. ${ }^{42}$
The roughness of restorative materials is associated with light reflection, surface staining, plaque accumulation, and patient discomfort. Plaque adhesion has been reported to significantly rise at a mean surface roughness of $0.2 \mu \mathrm{m} .{ }^{43}$ The direct relation between the surface roughness of the restorative material and the wear of opposing enamel, ${ }^{11,44}$ interpret the significance of studying the roughness values of materials used for fabricating crowns, before and after mastication. Additionally, Excessive wear of teeth, restoration or the entire dentition is usually related to supra eruption of opposing teeth, periodontal affection, traumatic occlusion, reduced vertical dimension and even temporomandibular joint disorders. ${ }^{45}$

Wiley ${ }^{46}$ observed that group function in porcelain could motivate group destruction. Therefore, the selection of the restorative material and its surface finish is of great importance. According to several studies smoothly glazed or highly polished ceramics reduced surface wear and damage of opposing teeth and restorations.$^{23,47-49}$ In this study, surface finishing of zirconia was performed by polishing rather than glazing therefore, although no significant difference, enamel cusp antagonist of Bruxzir group showed lower roughness change mean value $(0.016567 \pm 0.0013 \mathrm{Ra})$ than enamel cusp antagonist of gold alloy group mean value $(0.01867 \pm 0.024$ $\mathrm{Ra})$, at both low $(50 \mathrm{~N})$ and high $(150 \mathrm{~N})$ loads.

This was supported by various authors who have been suggested fine polishing as an alternative surface treatment of monolithic zirconia restorations; causing the least antagonistic tooth wear, whereas glazed zirconia caused greater antagonistic wear. ${ }^{10,32,50-54}$ Rupawala et al ${ }^{55}$ also compared the wear behavior of human tooth enamel opposing glazed zirconia, polished zirconia without glaze, metal ceramic, and lithium disilicate. It was observed that mechanically polished zirconia showed the least amount of enamel wear followed by porcelain fused to metal and glazed monolithic lithium disilicate, whereas glazed monolithic zirconia showed the highest enamel wear. In 
contrary, Beuer et al ${ }^{50}$ reported lower wear of the antagonist material with glazed monolithic zirconia.

Furthermore, higher enamel roughness change occurred with gold antagonist compared with bruxzir group could be attributed to lower hardness of gold than zirconia substrate. Therefore, a softer material is abraded more easily than harder material. ${ }^{56}$ Detached abraded particles might behave as an abrasive medium leading to a 3-body wear mechanism explaining the progression of enamel wear. ${ }^{57}$

Less susceptibility of zirconia to the microfracture mechanism because of the much high fracture resistance could be another explanation of lower enamel roughness and wear in case of zirconia. This was in agreement with several studies which reported that the zirconia surface did not become rougher over time, hence do not cause more wear on opposing enamel than other traditional softer ceramics. ${ }^{58-62}$

In the present study, regarding the roughness change results of zirconia and gold under high load $(150 \mathrm{~N})$, there was no significant difference, so the null hypothesis was supported. At low load chewing simulation, the null hypothesis was partially rejected, it was found that Bruxzir group recorded statistically significant lower roughness change mean value $(-0.00079 \pm 0.0023 \mathrm{Ra})$ than gold alloy group mean value $(0.00085 \pm 0.001 \mathrm{Ra})$. These results could be attributed to high fracture toughness of zirconia (5.5-7.4 Mpa.m ${ }^{1 / 2}$ ) which considered as a key of preventing micro fractures, cracks ${ }^{39}$ and subsequent surface roughness. ${ }^{63}$ Hence, the zirconia surface remains smoother during abrasive wear.

Other reasons for lower Ra change of zirconia are less porosity and smallest grain size of Bruxzir $(3 \mathrm{~nm})$, this concurs with $\mathbf{W u}$ et al ${ }^{64}$ who observed that grain or crystal size of ceramic material may contribute to obtain a smoother surface. He et al ${ }^{65}$ also reported that Y-TZP exhibits a Hall-Petch type of wear resistance relationship at grain sizes of $\leq 0.7$ $\mu \mathrm{m}$. This means that grain sizes of $0.7 \mu \mathrm{m}$ or smaller will make the material much more wear resistant by increasing the energy needed to remove the grain from the matrix of the ceramic. Similar results were obtained by Amer et al, ${ }^{66}$ who investigated the surface roughness changes of 3 types of ceramics: dense sintered yttrium stabilized zirconia, lithium disilicate and a conventional low-fusing feldspathic porcelain after being subjected to 3-body wearopposing human enamel. It was found that Y-TZP and lithium disilicate do not become as rough as conventional feldspathic porcelain of larger grains (2-4 $\mu \mathrm{m})$, when subjected to simulated mastication cycles.

It is also consistent with some investigators who demonstrated that microstructural parameters, such as grain size and porosity, are essential agents in the wear process. ${ }^{64,67}$ Zum et al ${ }^{68}$ showed that a decrease in the ceramic's grain size causes an increase in its wear resistance. Additionally, it was concluded that grain size and porosity are 2 important microstructural features which may influence the mechanical and tribological properties of the ceramic. ${ }^{69}$

Another interpretation of such result may be the low friction coefficient value of Y-TZP ceramic $(0.1 \mu \mathrm{m})$, this was supported by Anusavice et al ${ }^{70}$ who reported that the coefficient of friction is directly proportional to wear resistance and surface roughness.

\section{CONCLUSIONS}

Within the limitations of this in vitro study, the following conclusions were drawn:

1- Monolithic zirconia did not become as rough as type IV gold when subjected to simulated mastication cycles at low $(50 \mathrm{~N})$ load, although they were not significantly different from each other at high $(150 \mathrm{~N})$ load.

2- Although being non-significant, there was a correlation between roughness change of both monolithic zirconia and gold substrates, and that of their enamel antagonists. 


\section{REFERENCES}

1- Jacobi R, Shillingburg HT Jr, Duncanson MG Jr. A comparison of the abrasiveness of six ceramic surfaces and gold. J Prosthet Dent 1991;66:303-9.

2- Monasky GE, Taylor DF. Studies of the wear of porcelain, enamel, and gold. J Prosthet Dent 1971;25:299-306.

3- Conrad HJ, Seong WJ, Pesun IJ. Current ceramic materials and systems with clinical recommendations: a systematic review. J Prosthet Dent 2007;98: 389-404.

4- Schmitter M, Mussotter K, Rammelsberg P, Gabbert O, Ohlmann B. Clinical performance of long-span zirconia frameworks for fixed dental prostheses: 5-year results. J Oral Rehabil. 2012;39:552-557.

5- Zenthofer A, Ohlmann B, Rammelsberg P, B€omicke W. Performance of zirconia ceramic cantilever fixed dental prostheses: 3-year results from a prospective, randomized, controlled pilot study. J Prosthet Dent. 2015;114:34-39.

6- Bachhav VC, Aras MA. Zirconia-based fixed partial dentures: a clinical review. Quintessence Int. 2011; 42:173-182.

7- Sailer I, Feh/er A, Filser F, Gauckler LJ, L€uthy H, $\mathrm{H} €$ ammerle $\mathrm{CH}$. Five-year clinical results of zirconia frameworks for posterior fixed partial dentures. Int J Prosthodont. 2007;20: 383-388.

8- Al-Amleh B, Lyons K, Swain M. Clinical trials in zirconia: a systematic review. J Oral Rehabil. 2010;37:641-652.

9- Park JH, Park S, Lee K, Yun KD, Lim HL. Antagonist wear of three CAD/ CAM anatomic contour zirconia ceramics. J Prosthet Dent 2014;111:20-9.

10- Stawarczyk B, Ozcan M, Schmutz F, Trottmann A, Roos M, Hammerle CH. Two-body wear of monolithic, veneered and glazed zirconia and their corresponding enamel antagonists. Acta Odontol Scand 2013;71:102-12.

11- Elmaria A, Goldstein G, Vijayaraghavan T, Legeros RZ, and Hittelman E L. An evaluation of wear when enamel is opposed by various ceramic materials and gold . J Prosthet Dent 2006;96:345-53.

12- Sulong MZ, Aziz RA. Wear of materials used in dentistry: a review of the literature. J Prosthet Dent 1990;63:342-9.

13- Lambrechts P, Braem M, Vuylsteke-Wauters M, Vanherle G. Quantitative in vivo wear of human enamel. J Dent Res 1989;68:1752-4.
14- Yip KH, Smales RJ, Kaidonis JA. Differential wear of teeth and restorative materials: clinical implications. Int $\mathrm{J}$ Prosthodont 2004;17:350-6.

15- Metzler KT, Woody RD, Miller AW, Miller BH. In vitro investigation of the wear of human enamel by dental porcelain. J Prosthet Dent 1999;81:356-64.

16- DeLong R. Intra-oral restorative materials wear: Rethinking the current approaches: How to measure wear. Dent Mater 2006;22:702-11.

17- Gallegos LI, Nicholls JI. In vitro two-body wear of three veneering resins. J Prosthet Dent 1988;60:172-8.

18- Esquivel-Upshaw JF, Young H, Jones J, Yang M, Anusavice KJ. In vivo wear of enamel by a lithia disilicate-based core ceramic used for posterior fixed partial dentures: first-year results. Int J Prosthodont 2006;19:391-6.

19- Dahl BL, Oilo G. In vivo wear ranking of some restorative materials. Quintessence Int 1994;25:561-5.

20- Ramp MH, Suzuki S, Cox CF, Lacefield WR, Koth DL. Evaluation of wear: enamel opposing three ceramic materials and a gold alloy. J Prosthet Dent 1997; 77: 523-30.

21- Zeng J, Sato Y, Ohkubo C, Hosoi T. In vitro wear resistance of three types of composite resin denture teeth. J Prosthet Dent 2005;94:453-7.

22- Ogle RE, Davis EL. Clinical wear study of three commercially available artificial tooth materials: thirty-six month results. J Prosthet Dent 1998;79:145-51.

23- Hudson JD, Goldstein GR, Georgescu M. Enamel wear caused by three different restorative materials. J Prosthet Dent 1995;74:647-54.

24- Olivera AB, Marques MM. Esthetic restorative materials and opposing enamel wear. Oper Dent 2008;33:332-7.

25- DeLong R, Sasik C, Pintado MR, DouglasWH. The wear of enamel when opposed by ceramic systems. Dent Mater 1989;5:266-71.

26- Kelly JR, Nishimura I, Campbell SD.Ceramics in dentistry: historical roots and current perspectives. J Prosthet Dent 1996;75:18-32.

27- Kelly JR, Benetti P. Ceramic materials in dentistry: historical evolution and current practice. Aust Dent J. 2011;56(Suppl 1):84-96.

28- Probster L, Kern M. ZrO2 monoliths - a fascinating alternative? The trend towards fully anatomical oxide ceramic crowns. Dtsch Zahnarztl Z. 2012;67:777-782. 
29- Piconi C, Maccauro G. Zirconia as a ceramic biomaterial. Biomaterials 1999;20:1-25.

30- Guazzato M, Albakry M, Ringer SP, Swain MV. Strength, fracture toughness and microstructure of a selection of all ceramic materials. Part I. Pressable and alumina glassinfiltrated ceramics. Dent Mater 2004;20:441-8.

31- Jiang L, Liao Y, Wan Q, Li W. Effects of sintering temperature and particle size on the translucency of zirconium dioxide dental ceramic. J Mater Sci Mater Med. 2011;22:2429-2435.

32- Mitov G, Heintze SD, Walz S, Woll K, Mueklich F, Pospiech P. Wear behaviour of dental Y-TZP ceramic against natural enamel after different finishing procedures. Dent Mater 2012; 28:909-18.

33- Seghi RR, Rosenstiel SF, Bauer P. Abrasion of human enamel by different dental ceramics in vitro. J Dent Res $1991 ; 70: 221-5$.

34- Magne P, Oh WS, Pintado MR, DeLong R. Wear of enamel and veneering ceramics after laboratory and chairside finishing procedures. J Prosthet Dent 1999;82:669-79.

35- Miller GR, Powers JM, Ludema KC. Frictional behavior and surface failure of dental feldspathic porcelain. Wear 1975;31:307-16.

36- DeLong R, Douglas WH, Sakaguchi RL, Pintado MR. The wear of dental porcelain in an artificial mouth. Dent Mater 1986;2:214-9.

37- Buckly DH, Miyoshi K. Friction and wear of ceramics. Wear 1984;100: 333-53.

38- Fischer TE, Tomizawa H. Interaction of microfracture and tribochemistry in the friction and wear of silicon nitride. Wear 1985;105:29-45.

39- Fischer TE, Anderson MP, Jahanmir S. Influence of fracture toughness on the wear resistance of yttria doped zirconium oxide. J Am Ceram Soc 1989;72:252-7.

40- Harrison A. Wear of combinations of acrylic resin and porcelain, on an abrasion testing machine. J Oral Rehabil 1978;5:111-5.

41- Rabinowicz E. Friction and wear of materials. 2nd ed. New York: John Wiley; 1995. p. 113-23.

42- Lambrechts P, Braem M, Vanherle G. Buonocore memorial lecture. Evaluation of clinical performance for posterior composite resins and dentin adhesives. Oper Dent 1987;12:53-78.
43- Bollen CML, Lambrechts P, Quirynen M. Comparison of surface roughness of oral hard materials to the threshold surface roughness for bacterial plaque retention: A review of the literature. Dent Mater 1999;13:258-269.

44- Olivera AB, Matson E, Marques MM. The effect of glazed and polished ceramics on human enamel wear. Int $\mathrm{J}$ Prosthodont 2006;19:547-8.

45- Okeson JP. Management of Temporo-mandibular Disorders and Occlusion. St. Louis: Mosby; 1989. p. 259-60.

46- Wiley MG. Effects of porcelain on occluding surfaces of restored teeth. J Prosthet Dent 1989;61:133-7.

47- Oh W-S, DeLong R, Anusavice KJ. Factors affecting enamel and ceramic wear: A literature review. J Prosthet Dent 2002;87:451-459.

48- Al-Hiyasat AS, Saunders WP, Sharkey SW, Smith G, Gilmour WH. The abrasive effect of glazed, unglazed, and polished porcelain on the wear of human enamel, and the influence of carbonated soft drinks on the rate of wear. Int J Prosthodont 1997;10:269-282.

49- Chu FCS, Frankel N, Smales RJ. Surface roughness and flexural strength of self-glazed, polished, and reglazed In-Ceram/Vitadur Alpha porcelain laminates. Int $\mathrm{J}$ Prosthodont 2000;13:66-71.

50- Beuer F, Stimmelmayr M, Gueth JF, Edelhoff D, Naumann M. In vitro performance of full-contour zirconia single crowns. Dent Mater. 2012;28:449-456.

51- Preis V, Behr M, Handel G, Schneider-Feyrer S, Hahnel S, Rosentritt M. Wear performance of dental ceramics after grinding and polishing treatments. J Mech Behav Biomed Mater. 2012;10:13-22.

52- Janyavula S, Lawson N, Cakir D, Beck P, Ramp LC, Burgess JO. The wear of polished and glazed zirconia against enamel. J Prosthet Dent. 2013;109:22-29.

53- Kontos L, Schille C, Schweizer E, Geis-Gerstorfer J. Influence of surface treatment on the wear of solid zirconia. Acta Odontol Scand. 2013;71:482-487.

54- Sabrah AH, Cook NB, Luangruangrong P, Hara AT, Bottino MC. Full-contour Y-TZP ceramic surface roughness effect onsynthetic hydroxyapatite wear. Dent Mater. 2013;29:666-673.

55- Rupawala A, Musani SI, Madanshetty P, Dugal R, Shah UD, Sheth EJ. A study on the wear of enamel caused by monolithic zirconia and the subsequent phase transformation compared to two other ceramic systems. J Indian Prosthodont Soc 2017;17:8-14. 
56- Shimane T, Endo K, Zheng JH, Yanagi T, Ohno H. Wear of opposing teeth by posterior composite resins-evaluation of newly developed wear test methods. Dent Mater 2010; 29:713-20.

57- Ratledge DK, Smith BG, Wilson RF. The effect of restorative materials on the wear of human enamel. J Prosthet Dent 1994;72:194-203.

58- Clelland NL, Villarroel SC, Knobloch LA, Seghi RR. Simulated oral wear of packable composites. Oper Dent 2003; 28:830-7.

59- Clelland NL, Agarwala V, Knobloch LA, Seghi RR. Relative wear of enamel opposing low- fusing dental porcelain. J Prosthodont 2003;12:168-75.

60- al-Hiyasat AS, Saunders WP, Sharkey SW, Smith GM, Gilmour WH. Investigation of human enamel wear against four dental ceramics and gold. J Dent 1998;26:487-95.

61- Amer R, Kurklu D, Kateeb E, Seghi RR. Three-body wear potential of dental yttrium- stabilized zirconia ceramic after grinding, polishing, and glazing treatments. J Prosthet Dent 2014;112:1151-5.

62- Jung YS, Lee JW, Choi YJ, Ahn JS, Shin SW, Huh JB. A study on the in-vitro wear of the natural tooth structure by opposing zirconia or dental porcelain. J Adv Prosthodont 2010; 2:111-5.
63- Anusavice KJ. Phillips' science of dental materials. 12th ed. St Louis: Elsevier; 2013. p. 66, 284, 295, 453, 459-61.

64- Wu C CM, Rice RW, Johnson D, Platt BA. Grain size dependence and R-curve effects in the abrasive wear of alumina. J Am Ceram Soc 1985; 72:1249-52.

65- He Y, Winnubst L, Burggraaf AJ. Grain-size dependence of sliding wear in tetragonal zirconia polycrystals. J Am Ceram Soc 1996;79:3090-6.

66- Amer R, Kürklü D, Johnston W. Effect of simulated mastication on the surface roughness of three ceramic systems. J Prosthet Dent 2015;114:260-265.

67- Wu C CM, Rice RW. Porosity dependence of wear and other mechanical properties on fine-grain $\mathrm{A} 12 \mathrm{O} 3$ and B4C. Ceram Eng Sci Proc 1985;6: 977-94.

68- Zum Gahr KH, Bundschuh W, Zimmerlin B. Effect of grain size on friction and sliding wear of oxide ceramics. Wear 1993;162:269-79.

69- Zum Gahr KH. Sliding wear of ceramic-ceramic, ceramicsteel and steel-steel pairs in lubricated and unlubricated contact. Wear 1989;133:1-22.

70- Anusavice KJ, Shen C, Rawls HR. Phillips' science of dental materials. $12^{\text {th }}$ ed. St. Louis: Elsevier; 2013. p. 41866. 10. Zum Gahr KH. Sliding wear of ceramic. 